\title{
Release characteristics and bioactivity of gelatin-tricalcium phosphate membranes covalently immobilized with nerve growth factors
}

\author{
Pei-Ru Chen ${ }^{\mathrm{a}}$, Ming-Hong Chen ${ }^{\mathrm{a}, \mathrm{b}}$, Feng-Huei Lin ${ }^{\mathrm{a}, \mathrm{c}, *}, \mathrm{Wen}-\mathrm{Yu} \mathrm{Su}^{\mathrm{a}}$ \\ anstitute of Biomedical Engineering, College of Medicine, College of Engineering, National Taiwan University, Taipei, Taiwan \\ ${ }^{\mathrm{b}}$ Division of Neurosurgery, Department of Surgery, Cathay General Hospital, Taipei, Taiwan \\ ${ }^{\mathrm{c}}$ Department of Biomedical Engineering, National Taiwan University Hospital, Taipei, Taiwan
}

Received 9 December 2004; accepted 24 March 2005

\begin{abstract}
The gelatin-tricalcium phosphate membranes were cross-linking with low concentration glutaraldehyde solution (GTG). This material has good mechanical property, biocompatibility, and is feasible for surgical manipulation. For axonal regeneration, nerve growth factors (NGF) were immobilized onto the composite (GTG) with carbodiimide. The purpose of this study was to evaluate the release characteristics and bioactivity of NGF after covalent immobilization onto the GTG membranes (GEN). NGF immobilized onto and released from the composite was quantified using ELISA method. PC 12 cells were cultured on the GTG and GEN composites. Cell survival, cytotoxicity, and cellular activity were evaluated by total protein content, LDH activity, and MTT assay respectively. Neurite outgrowth assay was used to evaluate the biological activity of NGF released from GEN composite. From ELISA measurement, the releasing curve for NGF showing two distinctive parts with different slopes indicated that NGF were released from the composite in diffusion-controlled mechanism and degradation-controlled mechanism respectively. While culturing with PC 12 cells, LDH leakage results implied that whether GTG composite cross-linked with NGF or not showed little cytotoxicity. The total protein content and cellular activity of PC 12 cells were lower on GTG and GEN membranes than control group. However, $56 \% \pm 3.98$ of PC 12 cells showed significant neurite outgrowth on GEN membranes which was statistically higher than GTG without NGF immobilization. In addition, sustained release of bioactive NGF for two months had been demonstrated by neurite outgrowth assay. From these experiments, it can be concluded that the technique used in the present study is capable of immobilizing NGF onto GTG membranes covalently and remaining the bioactivity of NGF. Therefore, GEN composite can be materials for sustained release of bioactive NGF and a candidate for future therapeutic application in nerve repair.
\end{abstract}

(C) 2005 Elsevier Ltd. All rights reserved.

Keywords: Biodegradable nerve conduit; Nerve growth factor; PC 12 cell; Neurite outgrowth; NGF release

\section{Introduction}

Although the peripheral nervous system has a relatively good capacity to regenerate compared to the central nervous system, peripheral nerve repair remains a clinical challenge as restoration of normal nerve function is highly variable [1]. In clinical practice, direct

\footnotetext{
*Corresponding author. Institute of Biomedical Engineering, National Taiwan University, No.1, Sec. 1, Jen-Ai Road, Taipei, Taiwan, 100, R.O.C. Tel.: + 886223123456 1456; fax: + 886223940049 .

E-mail address: double@ha.mc.ntu.edu.tw (F.-H. Lin).
}

end-to-end suturing techniques are suggested for a short nerve injury. When large gaps remain between the ends of peripheral nerves, nerve autografting has been the first choice for repairing nerve gaps. However, the limited supply of available nerve autografts and certain donor site morbidity are its disadvantages. In addition, xenografts and allografts have poor successful rate and problems of immune rejection [2,3].

Synthetic guidance channels hold promise for replacing autologous nerve grafts and offer an "off-the-shelf" solution to avoid the sacrifice of a healthy nerve [4]. These tubes guide regenerating axons from the proximal 
toward the distal end, maintain within their lumen growth-promoting molecules released by the nerve stumps, and protect regenerating axons from infiltrating scar tissue. A wide range of materials has been developed for use as a synthetic nerve guidance channel. Of these materials, nondegradable materials such as silicone rubber have been widely used in general clinical case because of their inert and mechanical properties. However, upon completion of regeneration these materials may become detrimental due to mechanical impingement, foreign body reaction or infection [5]. Contrarily, biodegradable materials potentially avoid these problems. Biodegradable materials such as polyglycolic acid (PGA) [2] and polylactic acid (PLA) [6] are used for peripheral nerve regeneration. Nonetheless, upon degradation by hydrolysis, the products of PLA and PGA would lead to a low local $\mathrm{pH}$ and might hamper tissue regeneration [7,8]. Although collagen nerve guidance channel was successful in nerve repair $[9,10]$, collagen is rather expensive and difficult to handle during suturing because of inadequate mechanical strength.

With respect to collagen, gelatin is inexpensive and much easier to obtain in concentrate solutions. Moreover, gelatin is a biodegradable polymer with excellent biocompatibility. The ratio of gelatin and cross-linked reagents could be used to regulate the cross-linked degree and degradable rate. However, gelatin also has a problem in mechanical strength during operation.

A biodegradable composite as so-called glutaraldehyde solution (GTG) composite, glutaraldehyde crosslinked gelatin with tri-calcium phosphate (TCP) added to enhance the mechanical strength, has been developed in our laboratory as nerve guidance channel material for axon regeneration. GTG composite is a biodegradable material with a variety of attractive properties including good biocompatibility, no harm to Schwann cells [11], and good mechanical strength for surgical manipulation.

When a material designed as nerve guidance channel, incorporation of neurotrophic factors to improve axon regeneration should be considered. Nerve growth factor (NGF), one of neurotrophic factors, has been shown to enhance peripheral nerve regeneration and protected neurons from injury-induced death in lesioned sciatic nerves [12]. NGF also facilitates peripheral nerve regeneration in adult animals $[13,14]$. Moreover, NGF has also been shown to facilitate regeneration of hippocampal neurons across a peripheral nerve bridge $[15,16]$.

There are many research reports regarding NGF incorporation into materials. $\mathrm{Xu} \mathrm{X}$ et al. reported the preparation of NGF-encapsulated microspheres for the delivery of NGF [17]. However, the harsh conditions of the technique, namely exposure to organic solvents, may have unfavorable effects on the integrity of the growth factor and may result in deactivation during the encapsulation procedure or aggregation at the solventwater interface [18]. Heparin-binding growth factor delivery is a new method used for the release of certain growth factors [19], but NGF, brain-derived growth factors and neurotrophin-3 could not bind heparin effectively. In this study, carbodiimide reagent offers another method for generating cross-links between corresponding reaction sites, without itself being incorporated [20]. The carbodiimide is first protonated and reacts with the carboxyl groups on collagen to form the $o$-isoacylurea. This is followed by nucleophilic attack of the amine groups on the adjacent gelatin, generating the cross-link and releasing the urea derivative of the carbodiimide reagent. Therefore, proper washing steps to remove the activating reagent gave membrane no residual chemicals and no harm for cells or tissues [21].

In this work, NGF was immobilized onto the surface of GTG membrane (GEN) with carbodiimide. The biological activity and how long NGF released from GEN membrane will be examined by culturing PC 12 cells in vitro. MTT assay, total protein, LDH measurement and neurite outgrowth are in terms of cell viability, cell population, cell death and released NGF bioactivity, respectively. NGF immobilization efficiency and releasing mechanism will be determined by enzyme-linked immunosorbent assay (ELISA).

\section{Materials and methods}

\subsection{GTG membrane preparation}

GTG composite was prepared by adding $22.5 \mathrm{~g}$ of bovine gelatin (Sigma Chemical Co., St. Louis, MO, USA) to $380 \mathrm{ml}$ of de-ionized distilled water. The mixture was stirred at $400 \mathrm{rpm}$ with a magnetic bar of $1 \mathrm{~cm}$ in length and kept it at $70{ }^{\circ} \mathrm{C}$ until a homogenous gelatin solution was attained. TCP powder (Fluka, Chemika) was sintered at $900{ }^{\circ} \mathrm{C}$ and then sieved with 60-80 mesh to prepare the TCP particle for later application. $22.5 \mathrm{~g}$ of TCP particle was then added into the homogenous gelatin solution. The mixture was stirred for 5 min to ensure a uniform consistency. The temperature of the mixture was cooled to $35^{\circ} \mathrm{C}$, then, $22.5 \mathrm{ml} 1 \%$ glutaraldehyde solution was added for gelatin cross-linking [22]. The slurry was poured down into blank dishes and dried at the temperature of $50{ }^{\circ} \mathrm{C}$ overnight to form membranes. The GTG membrane was brittle and fragile with only one crosslinking step. This property of GTG membrane might be attributed to the retarded cross-linking by TCP particles. In order to achieve an ideal material for nerve guidance channels with good mechanical strength for surgical manipulation during suture and low degradation rate for the long period of slow nerve regeneration, the membranes were then soaked in $0.1 \%$ GTG for another $8 \mathrm{~h}$ for further cross-linking. The cross-linked GTG membrane was further treated with $0.1 \mathrm{M}$ glycine (Sigma Chemical Co., St. Louis, MO, USA) aqueous solution to block non-reacted aldehyde groups, and then 
washed with double-distilled water. The composite membranes were used in the later experiment for NGF grafting and PC12 cells seeding.

\subsection{The amount of NGF immobilized on GTG membrane (GEN membrane)}

To immobilize NGF (Chemicon Co., 7S NGF) onto GTG membrane, GTG membranes were soaked in $20 \mathrm{ml} 0.1 \mathrm{wt} \%$ 1-ethyl-3-(3-dimethylaminopropyl) carbodiimide (EDAC) solution for $24 \mathrm{~h}$ at $4{ }^{\circ} \mathrm{C}$. The membranes were then transferred to $5 \mathrm{ml} \mathrm{NGF}$ solution with different concentration of 10,30 , 50,70 and $100 \mathrm{ng} / \mathrm{ml}$ for $24 \mathrm{~h}$ at $4{ }^{\circ} \mathrm{C}$. The reaction of NGF with the primary carboxyl groups that existed on the surface of GTG membranes was initiated with EDAC. The proposed mechanism of NGF cross-linking is shown in Fig. 1. Steps of cross-linking with EDAC led to a covalent and stable binding between the carboxyl groups on the surface of GTG membrane and the amine groups of NGF. Unbound and excess EDAC was removed by washing the membranes with phosphate buffer solution (PBS) [11].

After NGF immobilized on GTG membrane (GEN membrane), the soaking solution was collected and measured by ELISA reader. The uncross-linked nerve growth factors (NGF) in the solution was calculated by ELISA using a calibration curve. The amount of NGF immobilized on the GTG membrane could be calculated by that the total NGF in the soaking solution for immobilization subtracted by the amount of uncross-linked NGF.

\subsection{NGF releasing study}

In $1 \mathrm{ml}$ PBS solution (pH 7.4) $10 \mathrm{~mm}^{2}$ of GEN membrane was immersed at $37{ }^{\circ} \mathrm{C}$. At each time interval, the solution was collected and replaced with fresh PBS. The collected PBS solution was stored at $-20^{\circ} \mathrm{C}$ for later analysis [23-25]. NGF in collected PBS solution was measured by ELISA reader. The NGF antibody in the ELISA kit (Chemicon Co., Nerve
Growth Factor sandwich ELISA kit) specifically reacts with the $\beta$-subunit of NGF in the 7S form and the total NGF would be detected [26,27]. The bioactivity of NGF released from GEN membrane was evaluated by neurite outgrowth of PC12 cell culture in Petri dish.

\subsection{Cell viability, cell population and LDH leakage test}

PC12 cells were cultured in RPMI 1640 medium (GIBCOBRL, RPMI medium 1640) with supplements of $10 \%$ heatinactivated horse serum, $5 \%$ fetal bovine serum and antibiotics [28]. Cells were maintained in a humid and $5 \% \mathrm{CO}_{2}$ incubator. PC1 2 cells were seeded on the 6-well culture dish at the density of $1 \times 10^{5}$ cells/well with $2 \mathrm{ml}$ culture medium addition.

GTG and GEN membranes were cut into a round shape as the size of culture well. The membranes were sterilized with $70 \%$ alcohol overnight and then washed with PBS. The experiment was divided into four groups $(n=18)($ Fig. 2$)$ and briefly described as follows: (1) PC12 cells cultured on GEN membrane (GEN group), (2) PC12 cells cultured on GTG membrane (GTG group), (3) PC12 cells cultured on Petri dish and $20 \mathrm{ng} / \mathrm{ml} \mathrm{NGF}$ added in medium (NGF group) [17], (4) PC12 cells cultured on Petri dish without NGF supplement as control group (control group).

Total protein content, LDH leakage and MTT assay were analyzed on day 1, 3, 7 after PC12 cells seeded to prove that the developed membranes were qualified for neuron regeneration. The test methods were shortly described as following sections.

\subsubsection{Total protein}

Eighty microliters of $0.5 \mathrm{~m} \mathrm{NaOH}$ were added to each well and then stayed in incubator overnight. $0.2 \mathrm{ml}$ medium was collected from each well and mixed with $2.2 \mathrm{ml}$ biuret solution in 96-well culture dish where $0.1 \mathrm{ml}$ Folin and Ciocalteu's Phenol Reagent (Sigma Chemical Co.) was added later [29]. The intensity of the color was read by ELISA reader at the wavelength of $700 \mathrm{~nm}$. Protein concentrations were determined from a calibration curve by interpolation method.

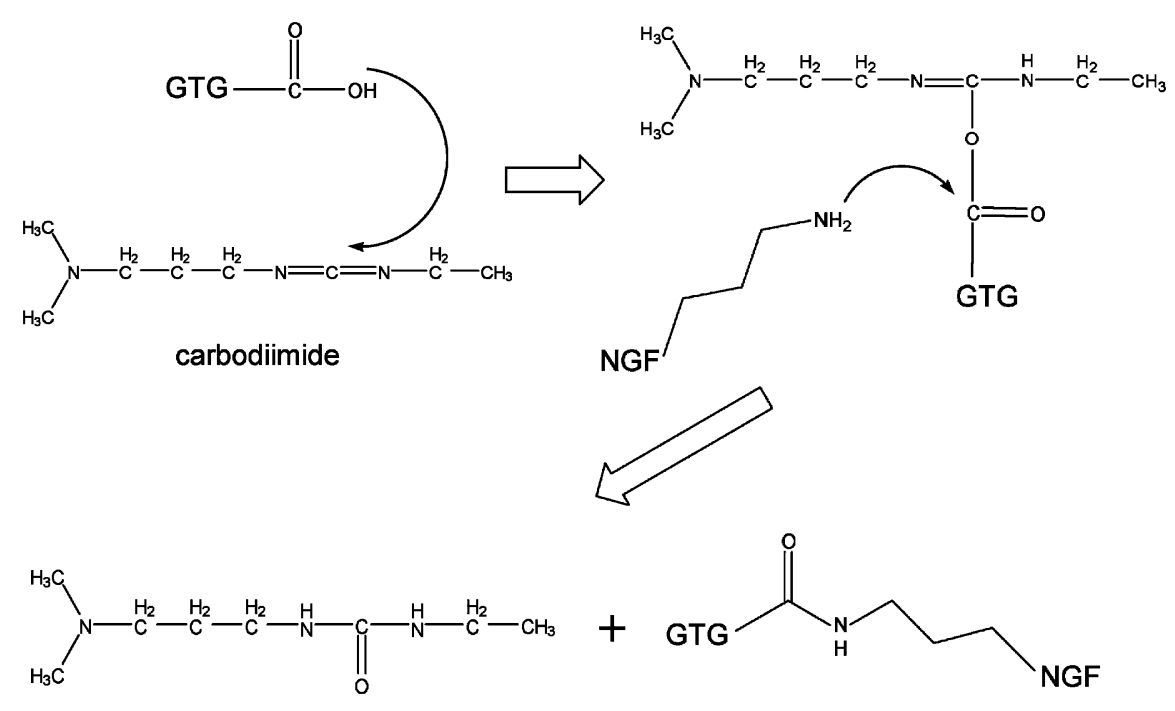

Fig. 1. Steps of cross-linking with carbodiimide led to a covalent and stable binding between the carboxyl groups on the surface of GTG membrane and the amine groups of NGF. 
I. GEN

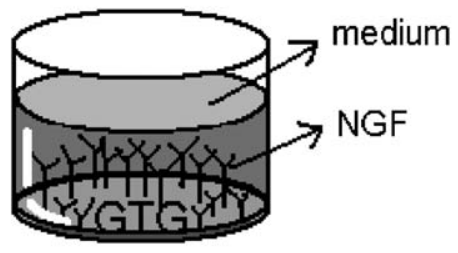

II. GTG

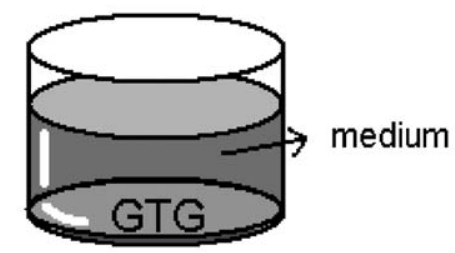

III. NGF (positive control)

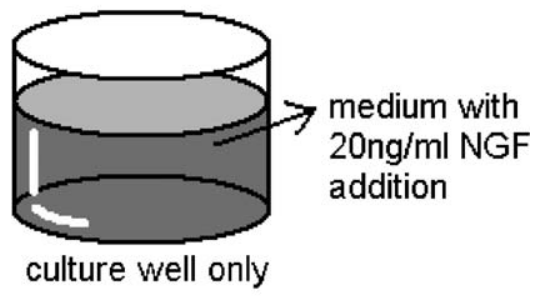

IV. Control (negative control)

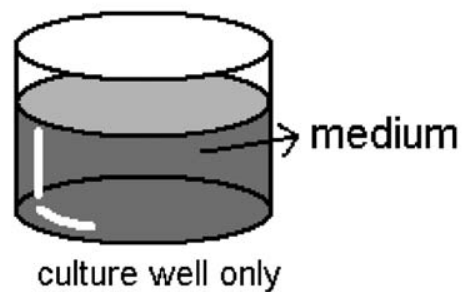

Fig. 2. Experimental groups: (1) PC12 cells cultured on GEN membrane (GEN group), (2) PC12 cells cultured on GTG membrane (GTG group), (3) PC12 cells cultured on Petri dish and $20 \mathrm{ng} / \mathrm{ml}$ NGF added in medium (NGF group), (4) PC12 cells cultured on Petri dish without NGF supplement as control group (control group).

\subsubsection{LDH leakage}

LDH catalyzes the oxidation of lactate to pyruvate with simultaneous reduction of nicotinamide adenine dinucleotide (NAD) resulting in an increase in absorbance at $340 \mathrm{~nm}$. PC12 cell injury was quantitatively assessed by the measurement of LDH leakage. $10 \mu \mathrm{l}$ of aliquots of the medium was mixed with $200 \mu \mathrm{LDH}$ reagent (Sigma Chemical Co.). LDH activity was calculated by measuring the increase in absorbance at $340 \mathrm{~nm}[30]$.

\subsubsection{MTT assay}

Fifty milligram of 3-(4,5-dimethylthiazol-2-yl)-2.5-diphenyl tetrazolium bromide (MTT, Sigma Chemical Co., St. Louis, MO, USA) was dissolved in $100 \mathrm{ml}$ PBS buffer to prepare MTT stock solution [31]. $0.35 \mathrm{ml}$ MTT stock solution was added to each well and stayed in incubator for $4 \mathrm{~h}$. The medium was removed. To each well $100 \mu \mathrm{l}$ of $0.04 \mathrm{~N} \mathrm{HCl} / \mathrm{EtOH}$ was added to break cells and turn the reaction product (formazan) into a purple solution. The purple solution was measured by ELISA plate reader (Labsystems Multiscan RC) at $570 \mathrm{~nm}$.

\subsection{Morphological evaluation and neurite outgrowth assay}

The morphology and neurite outgrowth of PC12 cell were used to evaluate the bioactivity of NGF releasing from GEN membrane. PC12 cells responded reversibly to NGF by differentiation into the neuronal phenotype extension of neurites. In this study, PC12 cells were cultured in the transwell (Corning Incorporated, NY) system. The composites as a source for the release of NGF were placed in the apical chamber of the transwell system. PC12 cells were cultured in the basal chamber. Therefore, as NGF were released via a diffusion mechanism or during the degradation of the composite, the bioactive NGF molecules in the medium could induce the differentiation of PC12 cells. After 7 days, the percentage of neurite-bearing cells was determined by counting about 200 cells in random fields using a Nikon digital camera and a computerized image analyzer. Neurite-bearing cells are those with processes greater than or equal to the cell body diameter [17,32].

\subsection{Statistical analysis}

All experiments were performed in a paired pattern and replicated with statistically meaningful times. The differences between various tested conditions were evaluated by the paired $t$-test. The level of statistical significance is defined as $p<0.05$.

\section{Results}

\subsection{The amount of NGF immobilized on GTG membrane}

In the study, the NGF solution of different concentration was used to immobilize the NGF molecules on the GTG membrane. From interpolation method, the amount of NGF immobilization was shown in Fig. 3. As shown in Fig. 3, the amount of NGF immobilized on the GTG membrane had no more increase once the concentration was up to $50 \mathrm{ng} / \mathrm{ml}$. The curve (Fig. 3) is stepped into a plateau if concentration higher than $50 \mathrm{ng} / \mathrm{ml}$. The $50 \mathrm{ng} / \mathrm{ml} \mathrm{might}$ the optimum concentration for NGF immobilized onto GTG membrane. 


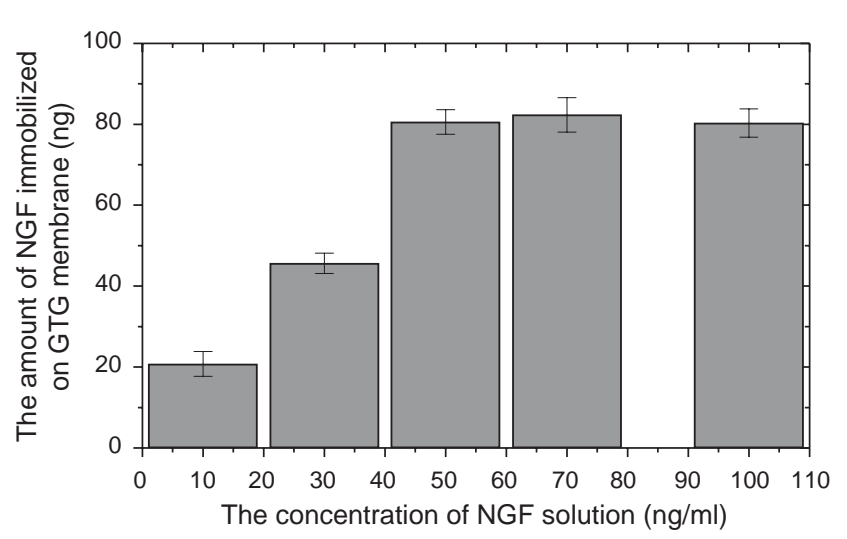

Fig. 3. The amount of NGF immobilized on GTG membrane $(n=5)$.

\subsection{NGF releasing}

The amount of NGF released from GEN membrane was analyzed by ELISA reader and the test extended for 60 days (Fig. 4). The burst releasing happened at the first day about $16 \%$ in accumulative percentage. The releasing rate was slow down thereafter. At the end of 30 days, $26.5 \%$ of the total NGF in average was released. NGF was constantly released from GEN membrane and could be traced with minimum neurite outgrowth concentration even after 60 days. At end of the 60th day, about $34 \%$ of the total NGF was released. The releasing curve shows two distinctive parts with different slope which reflects the two different releasing mechanisms. The daily releasing rate was schemed as Fig. 5. At the first day, $13 \mathrm{ng} /$ day of NGF in average was released from GEN membrane. From day 2 to day $10,1.35 \mathrm{ng} /$ day of NGF in average was released from the membrane. After day 10, the minimum daily releasing of NGF is $0.4 \mathrm{ng}$ in average.

\subsection{Total protein analysis}

Fig. 6 shows the total protein analysis after PC12 cell cultured for 1, 3 and 7 days. At the first day, the total protein content of GEN, GTG, NGF, and control group is $1.38,1.17,1.52$ and $1.68 \mathrm{mg} / \mathrm{ml}$ in average, respectively. The values showed no significant difference based on statistical analysis. At the $3 \mathrm{rd}$ day, the value for the four test groups is 2.04, 2.20, 2.71 and $2.85 \mathrm{mg} / \mathrm{ml}$, respectively. At day 7 , the value for total protein is $2.80,2.70,3.27$ and $3.33 \mathrm{mg} / \mathrm{ml}$ for the four test groups, respectively. From the test results, there were no statistic differences for all the test groups at the first day. After cultured for 3 days and 7 days, the total protein content of GEN and GTG groups were significantly lower than that of NGF and control groups.

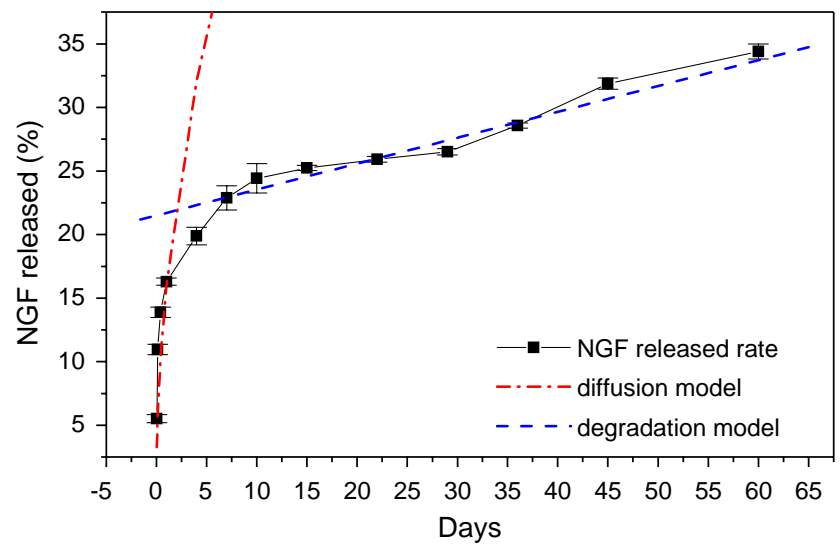

Fig. 4. The NGF releasing curve. In vitro cumulative release of NGF from GEN membrane, $10 \times 10 \mathrm{~mm}$.

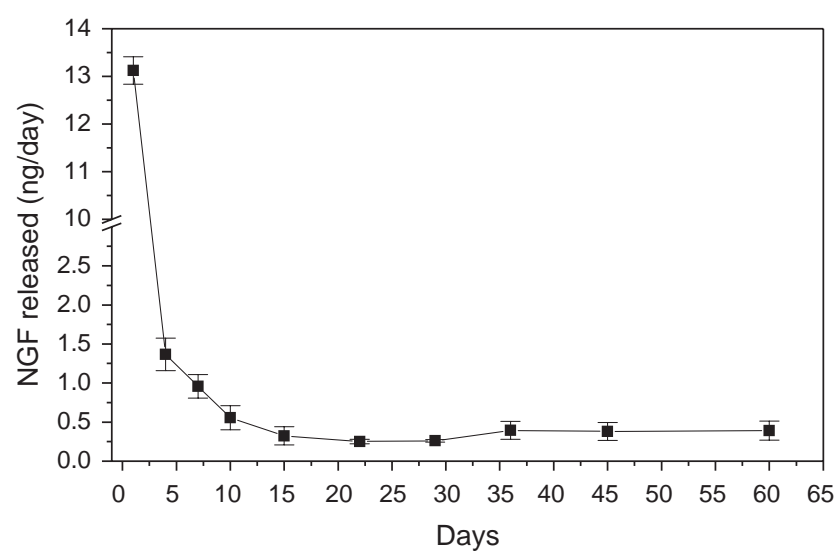

Fig. 5. Daily in vitro release of NGF from GEN membrane, $10 \times 10 \mathrm{~mm}$. Total drug content $80.57 \mathrm{ng}, \mathrm{pH} 7.4$ and $37^{\circ} \mathrm{C}$.

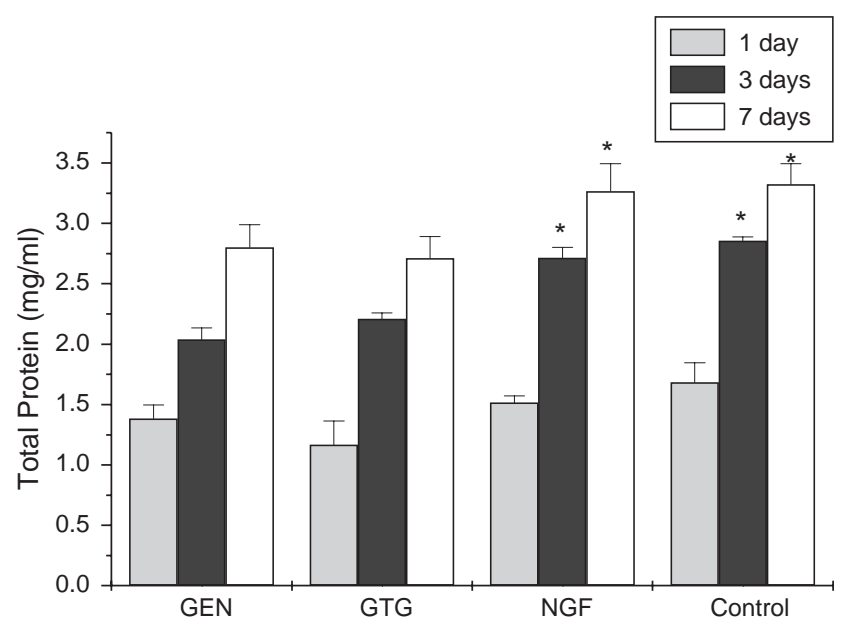

Fig. 6. Total cell protein test. It showed the effects of various membranes on the protein content of PC12 cells after 1, 3, 7 days of culture. In GEN and GTG groups, the PC12 cells protein contents were a bit less than control group and NGF group. 


\subsection{MTT assay}

Fig. 7 shows the MTT assay for the four test groups after cultured for 1, 3 and 7 days. At the first day, the MTT value for GEN, GTG, NGF, and control group is $0.25,0.21,0.36$, and 0.40 , respectively. At the 3rd day, the value for the 4 test groups is $0.44,0.45,0.52$, and 0.53 , respectively. At day 7 , the value for the 4 test groups is $0.52,0.55,0.67$ and 0.63 , respectively. From the statistical analysis, MTT value for the test groups has significant difference in each test time period. The MTT value to each test group increases with the cultured time. The MTT value of GEN and GTG is much lower than that of the NGF and control group.

\subsection{LDH leakage analysis}

As an intracellular enzyme, LDH was released only when cellular injury occurred. The leakage of LDH into culture medium provides an accurate and sensitive marker related with cell death [33]. As shown in the Fig. 8, the LDH leakage has no significant difference among 4 groups. The LDH concentration is in the range of $2.57-3.98 \mathrm{U} / \mathrm{dl}$. There is no significant difference among each group and test time period.

\subsection{PC12 cells neurite outgrowth measurement}

The neurite outgrowth of PC12 cells was used to examine whether the released NGF kept its bioactivity as supplement to promote neurite outgrowth. The numbers of neurite-bearing cells were calculated with image processing software. After cultured for 7 days, about $56 \%$ and $61 \%$ of $\mathrm{PC} 12$ cells showed neurite growth in GEN group and NGF group, respectively. In the contrary, less than $5 \%$ of $\mathrm{PC} 12$ cells shows fiber outgrowth in GTG and control group. As shown in Fig. 9, the neurite outgrowth of PC12 cells showed great difference between the groups with and without NGF.

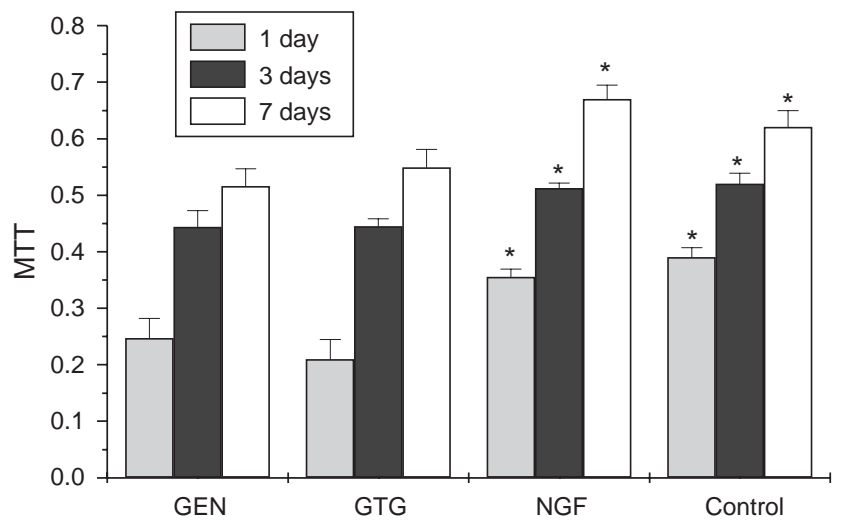

Fig. 7. The MTT-tetrazolium assay. After 1, 3, 7 days of PC12 cells culture, the cell activities in GEN and GTG groups were a bit less than control group and NGF group.

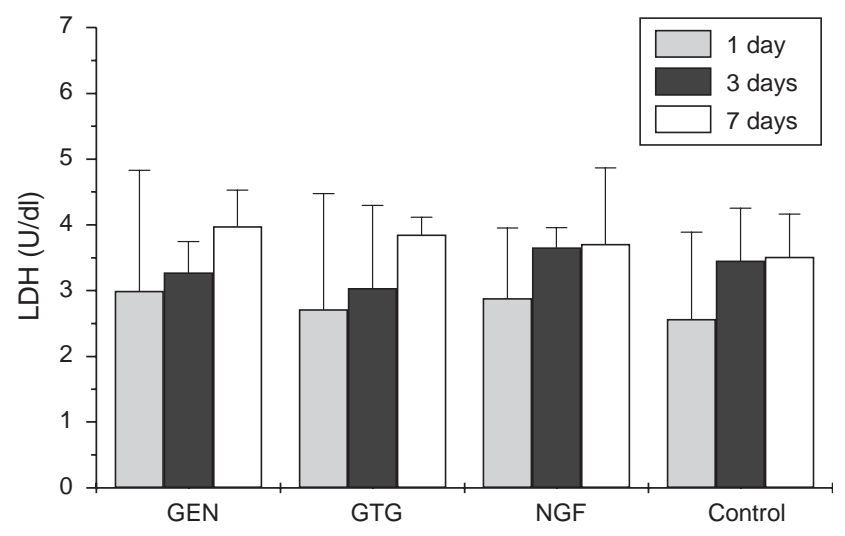

Fig. 8. LDH release test. The differences in LDH leakage were not statistically significant among all the 4 groups.

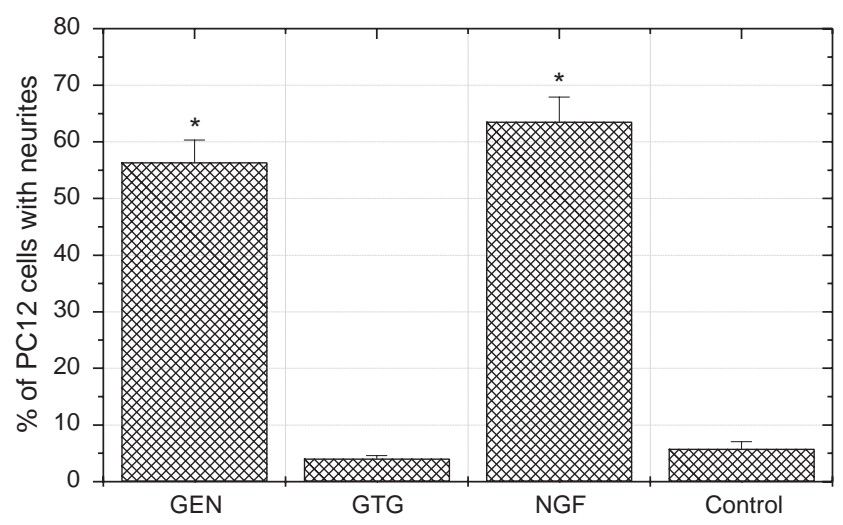

Fig. 9. The numbers of neurite-bearing cells were counted and compared with NGF group and control group. The bioactivity of NGF was maintained on the GEN membranes, as demonstrated by neurite outgrowth in $56 \%$ of $\mathrm{PC} 12$ cells after stimulation with the medium of NGF released.

The bioactivity of NGF was maintained on the GEN membranes, as demonstrated by neurite outgrowth in $56 \%$ of PC12 cells after stimulation with the medium of NGF released.

\section{Discussion}

From the result of Fig. 3, the optimum NGF concentration in soaking solution for NGF immobilization was $50 \mathrm{ng} / \mathrm{ml}$. The linking between NGF molecule and gelatin molecule is through the carboxyl group and amino group on the two molecules with the help of carbodiimide (Fig. 1). Due to limited functional groups on the two molecules, the number of NGF molecules bound to gelatin molecules is limited as well so that the number of NGF immobilized on the GTG membrane is increasing with the NGF concentration of the soaking solution at the first until $50 \mathrm{ng} / \mathrm{ml}$ and reach to a plateau 
thereafter. There was about $80.57 \mathrm{ng}$ of NGF grafted on the GTG membrane.

As shown in Figs. 4 and 5, the curve of NGF releasing from the GEN membrane could be divided into a two distinct parts with different slope. In the study, NGF molecules bound to membrane with two mechanisms. The one is physical adsorption based on electrostatic attraction force between opposite charge residual groups both on NGF and gelatin molecules. In the first part of the curve, the NGF releasing from GEN membrane showed an initial burst due to the physical adsorption NGF dissociate from the membrane. The releasing is a quick release and based on concentration gradient. Basically, it follows the Fick's law. The releasing behavior will stop within relative short term once the concentration gradient is disappeared. Mathematical modeling of NGF diffusion through a rate-limiting membrane has been well documented [34]. In the case of slab geometry, NGF releasing in early time can be described by the following equation [34]:

$\frac{M_{t}}{M_{\infty}}=4\left(\frac{D t}{\pi r^{2}}\right)^{1 / 2}$,

where $M_{t}$ is the amount if NGF released in time $t, M_{\infty}$ is the cumulative amount of drug released as time approaches infinity, $D$ is the diffusion coefficient of a drug, $\pi$ is 3.14, and $r$ is the thickness of the device. The thickness $(r)$ of GEN membrane was about $160 \mu \mathrm{m}$. Eq. (1) is an early time approximation which holds for the release at the first days in this study. From curve fitting in Fig. 4, the value of $D, 0.0009$, was figured out by computer software. From the $D$ value, we can predict the amount of NGF releasing from the different thickness of GEN membrane for the future applications.

In the second part of the curve in Figs. 4 and 5, the releasing rate is much slower than the first part. As shown in Fig. 1, the bonding between NGF molecules and gelatin molecule is amide bond. The bonding will be gradually disrupted by hydrolysis and enzymatic degradation. We can expect the releasing behavior is more close to degradation-controlled monolithic model. The degradation is generally started from the membrane surface. For surface-degrading systems, the kinetic expression describing NGF releasing from the membrane can be given by [34]

$\frac{M_{t}}{M_{\infty}}=\frac{k_{0} t}{C_{0} a}$,

where $k_{0}$ is a rate constant, $C_{0}$ is the uniform initial concentration of NGF and $a$ is the initial radius. From our calculation, it is apparent that the membrane device provides a zero-order NGF releasing at day 7 to day 60 . The NGF releasing at day 2 to day 7 was the overlapped period between diffusion model and surface-degradation model. From the study, about $66 \%$ of NGF will be continuously released from the GEN membrane after 2 months. The rest of NGF molecules should expect to be released from the GEN membrane at a rate as the slope indicated on the second part of the curve (Fig. 4) based on degradation-controlled model.

As previous report, effective NGF to stimulate PC12 cell neurite outgrowth is in the range of $0.1-50 \mathrm{ng} / \mathrm{ml}$ [35,36]. As shown in Fig. 5, the minimum amount of NGF releasing from the GEN membrane is about $0.4 \mathrm{ng}$. Therefore, the daily concentration of NGF releasing from GEN membrane reached the effective concentration to stimulate the neurite outgrowth.

From the result of LDH test (Fig. 8), GTG and GEN membrane will not cause PC12 cells to death. The glutaraldehyde cross-linked gelatin membrane treated with $0.1 \mathrm{M}$ glycine solution to block non-reacted aldehyde group is believed to play an important role to remove the toxicity. The NGF immobilization with the help of carbodiimide also showed no toxicity to the PC12 cell. However, the gelatin membrane turned to more hydrophobic surface after cross-linked by aldehyde group. The hydrophobic surface of the membrane might be resulted in poor cell adhesion. As shown in the MTT test (Fig. 7), the GEN and GTG groups showed lower OD value than that of the NGF and control group. The total protein analysis has no statistical difference at the first day but showed significant different at the 3 rd day and 7 th day due to the value of total protein analysis included death cell.

Nerve growth factor, the prototypical member of the neurotrophin family, promoted the survival and neurite outgrowth of neurons [37]. The events following NGF binding to their respective receptors stems from research on the response of NGF binding to PC 12 cells. PC 12 cells are derived from a rat pheochromocytoma cell line, express trkA (tropomyosin receptor kinase) and p75 receptors, and respond to NGF by differentiating into cells that resemble adult neurons $[38,39]$. As NGF activation of trkA on PC 12 cells, additional downstream signaling with activation of SNT is involved in neurite outgrowth [40]. In order to avoid NGF deactivation, we kept the temperature for reaction at $4{ }^{\circ} \mathrm{C}$ during the process of NGF immobilization. Nevertheless, we still had to verify the bioactivity of NGF after the procedures of immobilization. As we know, the $\beta$-NGF subunit possesses all of the biological activity of $7 \mathrm{~S}$ NGF molecule [35]. With the ELISA tests for the $\beta$ NGF subunit, the biological activity of NGF molecules which released in the medium could be confirmed. Furthermore, as shown in the neurite outgrowth assay (Fig. 9), there is no obvious neurite outgrowth in the GTG and control group without the stimulation from NGF molecules. In the contrary, NGF and GEN groups all present a high ratio neurite outgrowth. The result is in agreement with the previous founding that NGF could promote the neurite outgrowth. NGF still had the bioactivity to PC12 cells and the procedure of 
immobilizing NGF onto GTG membrane in this study was reliable.

\section{Conclusion}

In this study, the NGF molecules were successfully immobilized on the GTG membrane with the help of the carbodiimide. After immobilized, the NGF molecules can be released from the membrane at least for 60 days. The releasing curve can be divided into two parts with two releasing mechanisms. The one is based on diffusion-controlled model due to dissociate from the physical adsorption. The latter is believed to be surfacedegradation model. The GEN membrane is not harmful to the PC12 cell and will not cause to death. The NGF releasing from the membrane still keeps bioactivity that promotes the neurite outgrowth of $\mathrm{PC} 12$ cell. In the future, we believe that the GEN membrane is one of potential material as nerve guidance channel to promote axonal regeneration for injured peripheral nerve.

\section{References}

[1] Bloch J, Fine EG, Bouche N, Zurn AD, Aebischer P. Nerve growth factor- and neurotrophin-3-releasing guidance channels promote regeneration of the transected rat dorsal root. Exp Neurol 2001;172(2):425-32.

[2] Mackinnon SE, Dellon AL. Clinical nerve reconstruction with a bioabsorbable polyglycolic acid tube. Plast Reconstr Surg 1990; 85(3):419-24.

[3] Evans PJ, Mackinnon SE, Levi ADO, Wade JA, Hunter DA, Nakao Y, Midha R. Cold preserved nerve allografts: changes in basement membrane, viability, immunogenicity, and regeneration. Muscle Nerve 1998;21(11):1507-22.

[4] Raivich G, Kreutzberg GW. Nerve growth factor and regeneration of peripheral nervous system. Clin Neurol Neurosurg 1993; 95:84-8.

[5] Merle M, Dellon AL, Campbell JN, Chang PS. Complications from silicon-polymer intubulation of nerves. Microsurgery 1989;10(2):130-3.

[6] Madison R, Da Silva CF, Dikkes P, Chiu T-H, Sidman RL. Increased rate of peripheral nerve regeneration using bioresorbable nerve guides and a laminin-containing gel. Exp Neurol 1985;88(3):767-72.

[7] Agrawal CM, Athanasiou KA. Technique to control $\mathrm{pH}$ in vicinity of biodegrading PLA-PGA implants. J Biomed Mater Res 1997;38(2):105-14.

[8] Suganuma J, Alexander H. Biological response of intramedullary bone to poly L-lactic acid. J Appl Biomater 1993;4:13-27.

[9] Colin W, Donoff RB. Nerve regeneration through collagen tubes. J Dental Res 1984;63(7):987-93.

[10] Itoh S, Takakuda K, Kawabata S, Aso Y, Kasai K, Itoh H, Shinomiya K. Evaluation of cross-linking procedures of collagen tubes used in peripheral nerve repair. Biomaterials 2002;23(23): 4475-81.

[11] Chen P-R, Chen M-H, Sun J-S, Chen M-H, Tsai C-C, Lin F-H. Biocompatibility of NGF-grafted GTG membranes for peripheral nerve repair using cultured Schwann cells. Biomaterials 2004;25: $5667-73$.
[12] Otto D, Unsicker K, Grothe C. Pharmacological effects of nerve growth factor and fibroblast growth factor applied to the transectioned sciatic nerve on neuron death in adult rat dorsal root ganglia. Neurosci Lett 1987;83:156-60.

[13] Rich KM, Alexander TD, Pryor JC, Hollowell JP. Nerve growth factor enhances regeneration through silicone chambers. Exp Neurol 1989;105(2):162-70.

[14] Derby A, Wayne Engleman V, Frierdich GE, Neises G, Rapp SR, Roufa DG. Nerve growth factor facilitates regeneration across nerve gaps: morphological and behavioral studies in rat sciatic nerve. Exp Neurol 1993;119:176-91.

[15] Varon S, Conner JM. Nerve growth factor in CNS repair. J Neurotrauma 1994;11:473-86.

[16] Lee AC, Yu VM, Lowe III JB, Brenner MJ, Hunter DA, Mackinnon SE, Sakiyama-Elbert SE. Controlled release of nerve growth factor enhances sciatic nerve regeneration. Exp Neurol 2003;184:295-303.

[17] $\mathrm{Xu} \mathrm{X,} \mathrm{Yu} \mathrm{H,} \mathrm{Gao} \mathrm{S,} \mathrm{Mao} \mathrm{H-Q,} \mathrm{Leong} \mathrm{KW,} \mathrm{Wang} \mathrm{S.}$ Polyphosphoester microspheres for sustained release of biologically active nerve growth factor. Biomaterials 2002;23: 3765-72.

[18] Whitaker MJ, Quirk RA, Howdle SM, Shakesheff KM. Growth factor release from tissue engineering scaffolds. J Pharmacy Pharmacol 2001;53:1427-37.

[19] Sakiyama SE, Hubbell JA. Development of fibrin derivatives for controlled release of heparin-binding growth factors. J Control Rel 2000;65:389-402.

[20] Khor E. Methods for the treatment of collagenous tissues for bioprostheses (review). Biomaterials 1997;18:95-105.

[21] Mann BK, Schmedlen RH, West JL. Tethered-TGF- $\beta$-increases extracellular matrix production of vascular smooth muscle cells. Biomaterials 2001;22:439-44.

[22] Lin F-H, Yao C-H, Sun J-S, Liu H-C, Huang C-W. Biological effects and cytotoxicity of the composite composed by tricalcium phosphate and glutaraldehyde cross-linked gelatin. Biomaterials 1998;19:905-17.

[23] Bigi A, Cojazzi G, Panzavolta S, Rubini K, Roveri N. Mechanical and thermal properties of gelatin films at different degrees of glutaraldehyde crosslinking. Biomaterials 2001;22:763-8.

[24] Breitenbach A, Li YX, Kissel T. Branched biodegradable polyesters for parenteral drug delivery systems. J Control Release 2000;64:167-78.

[25] Chinen N, Tanihara M, Nakagawa M, Shinozaki K, Yamamoto E, Mizushima Y, Suzuki Y. Action of microparticles of heparin and alginate crosslinked gel when used as injectable artificial matrices to stabilize basic fibroblast growth factor and induce angiogenesis by controlling its release. J Biomed Mater Res 2003; 67A:61-8

[26] Zettler C, McLeod Bridges DC, Zhou X-F, Rush RA. Detection of increased tissue concentrations of Nerve Growth Factor with an improved extraction procedure. Journal of Neuroscience Research 1996;46:581-94.

[27] Harada T, Harada C, Kohsaka S, Wada E, Yoshida K, Ohno S, Mamada H, Tanaka K, Parada LF, Wada K. Microglia-Muller glia cell interactions control neurotrophic factor production during light-induced retinal degeneration. J Neurosci 2002;22: 9228-36.

[28] Biocca S, Cattaneo A, Calissano P. A macromolecular structure favouring microtubule assembly in NGF-differentiated pheochromocytoma cells (PC12). EMBO J 1983;2:643-8.

[29] Ohnishi ST, Barr JK. A simplified method of quantitating protein using the biuret and phenol reagents. Anal Biochem 1978;86(1): 193-200.

[30] Amador E, Dorfman LE, Wacker WEC. Serum lactic dehydrogenase: an analytical assessment of current assays. Clin Chem 1963;9(4):391-9. 
[31] Mosmann T. Rapid colorimetric assay for cellular growth and survival: application to proliferation and cytotoxicity assays. J Immunol Methods 1983;65(1-2):55-63.

[32] Hall FL, Fernyhough P, Ishii DN, Richard Vulliet P. Suppression of nerve growth factor-directed neurite outgrowth in PC12 cells by sphingosine, an inhibitor of protein kinase C. J Biol Chem 1988;263(9):4460-6.

[33] Rae T. A study on the effects of particulate metals of orthopaedic interest on murine macrophages in vitro. J Bone Jt Surg 1975; 57-B(4):444-50.

[34] Park K, Shalaby WSW, Park H. Biodegradable drug delivery systems. Biodegradable Hydrogels for Drug Delivery 1993;189-232.

[35] Darling TL, Shooter EM. Methods for preparation and assay of nerve growth factor. In: Barnes DW, Sinbasku DA, editors. Cell culture methods for molecular and cellular biology. New York: Alan R. Liss, Inc.; 1984. p. 79-93.
[36] Varon S, Nomura J, Shooter EM. The isolation of the mouse nerve growth factor protein in a high molecular weight form. Biochemistry 1967;6(7):2202-9.

[37] Levi-Montalcini R, Hamburger C. A diffusable agent of mouse sarcoma, producing hyperplasia of sympathetic ganglia and hyperneurotization of viscera in the chick embryo. J Exp Zool 1953;123:233-88.

[38] Tischler AS, Greene LA. Nerve growth factor-induced process formation by cultured rat pheochromocytoma cells. Nature 1975; 258:341-2.

[39] Greene LA, Tischler AS. Establishment of a noradrenergic clonal line of rat adrenal phreochromocytoma cells which respond to nerve growth factor. Proc Natl Acad Sci USA 1976;73:2424-8.

[40] Peng X, Greene LA, Kaplan DR, Stephens RM. Deletion of a conserved juxtamembrane sequence in Trk abolishes NGFpromoted neuritogenesis. Neuron 1995;15:395-406. 